\title{
Fault Estimation on Induction Motor Based on Stator Inter-Turn Fault
}

\author{
Bambang Lelono Widjiantoro, Syahrul Munir and Katherin Indriawati \\ Department Engineering Physics, Institut Teknologi Sepuluh Nopember, Surabaya \\ e-mail: munir.18023@mhs.its.ac.id
}

\begin{abstract}
Since the 19th century, the use of electric motors continues to grow. Nowadays electric motors have been widely used in various fields of industry. One type of electric motor that is often used is an induction motor. Induction motors work in the presence of induced currents due to the relative difference in rotor rotation with rotating magnetic fields. Induction motors are preferred for industrial purposes because of low cost, easy to maintain, and high efficiency. Induction motors that are used continuously can experience several types of fault. The existence of fault can affect the performance of the induction motor. One of the fault that often occurs in induction motor is the result of stator inter-turn fault. This fault is caused by the gradual deterioration of insulation in the stator winding which cause a short-circuit. Sooner or later, this fault can cause damage to the induction motor in a short time if left unchecked. So, it is very important to monitor the fault in real-time. Therefore, this research proposes a fault estimation method on induction motor. The design of fault estimation based on particle filtering and extended state space equations is used to estimate the stator inter-turn fault. The effectiveness of this approach is validated by use of a computer simulation with using two fault signal represented by $\eta_{c c}$ ramp and step signal. The performances of this fault estimation are measured by RMSE and with using 500 particles has smallest RMSE value, which are 0.0112 and 0.0124 for dq current fault when using $\eta_{\text {cc }}$ ramp signal and 0.2373 and 0.2367 for dq current fault when using $\eta_{c c}$ step signal.
\end{abstract}

Keywords-Induction Motor, Particle Filtering, Stator InterTurn Fault.

\section{INTRODUCTION}

$\mathrm{S}$ INCE the $19^{\text {th }}$ century, the use of electric motors continues to grow. Nowadays electric motors have been widely used in various fields of industry. One type of electric motor that is often used is an induction motor. Induction motor is a device that is able to convert electrical energy into mechanical energy. Induction motors work in the presence of induced currents due to the relative difference in rotor rotation with rotating magnetic fields. Induction motors are preferred for industrial purposes because of low cost, easy to maintain, and high efficiency. Induction motors that are used continuously can experience several types of fault. The existence of fault can affect the performance of the induction motor.

Faults that occur in induction motors can be categorized into mechanical and electrical faults [1]. Mechanical faults can be bearing damage or defects in the shaft. While electrical faults can be categorized again into stator and rotor faults. The rotor fault can be in the form of demagnetization from permanent magnets to damage to the rotor bar. Stator faults can be defects in the stator windings or defects in the stator

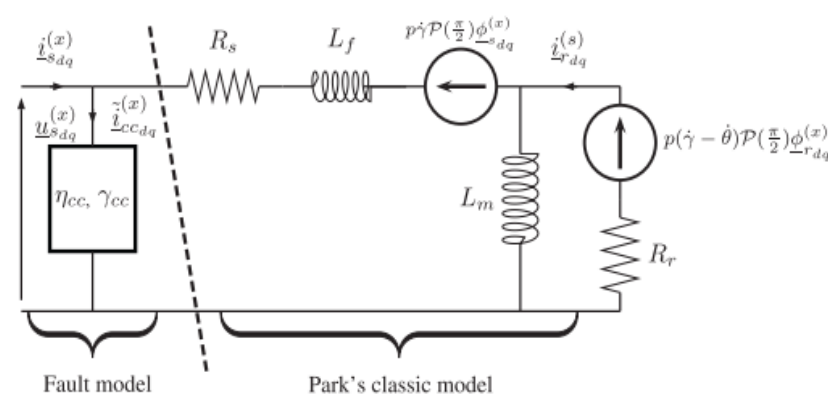

Figure 1. Electrical diagram of faulty induction motor.

core. Based on Kliman, et.al (2002) [2], about 35\% of the most common fault are faults on the stator winding.

One type of fault in the stator winding is due to a stator inter-turn winding fault. This fault is caused by the gradual deterioration of insulation in the stator winding which results in short-circuit [3]. If this happens, it causes a high load current and increases the workload of the induction motor. In the end, this fault will cause damage to the induction motor in a short time if left unchecked [4].

For avoiding damage by this possible fault on system, the technique of fault detection has been continuously developed to improving safety and reliability of the system. One of the technique of fault detection is particle filtering (PF). $\mathrm{PF}$ is a nonlinier filtering alghorithm that widely used for nonlinier dynamic system's state estimation in control and signal processing areas [5]. Because induction motor is a nonlinier dynamic system, PF is suitable to used for this research. Hence, this research use PF to estimate the fault on induction motor based on stator inter-turn winding fault.

\section{RESEARCH METHOD}

\section{A. Stator Inter-Turn Fault Modelling on Induction Motor}

Stator inter-turn fault modelling is done by modifying induction motor model in healthy condition proposed in Chan and Shin (2011) [6] with the short-circuit equation proposed in Schaeffer and Bachir (2013) [7]. The electrical diagram of faulty induction motor can be seen in Figure 1.

It is noticed that from the electrical diagram before that the fault is similar to a simple error on the current measurement in healthy induction motor model. The state space representation of this faulty model is

$\dot{x}=A x+B u$

$y=C x+D u$

where 


$$
\begin{aligned}
x & =\left[\begin{array}{cccccc}
i_{s d} & i_{s q} & \lambda_{r d} & \lambda_{r q} & \omega_{r}
\end{array}\right]^{T}, u=\left[\begin{array}{l}
V_{s d} \\
V_{s q}
\end{array}\right] \\
A & =\left[\begin{array}{ccccc}
-\frac{L_{m}{ }^{2} R_{r}+L_{r}{ }^{2} R_{s}}{\sigma L_{r}{ }^{2} L_{s}} & \omega_{s} & \frac{L_{m} R_{r}}{\sigma L_{r}{ }^{2} L_{s}} & \frac{p L_{m}}{\sigma L_{r} L_{s}} \omega_{r} & 0 \\
\omega_{s} & -\frac{L_{m}{ }^{2} R_{r}+L_{r}{ }^{2} R_{s}}{\sigma L_{r}{ }^{2} L_{s}} & -\frac{p L_{m}}{\sigma L_{r} L_{s}} \omega_{r} & \frac{L_{m} R_{r}}{\sigma L_{r}{ }^{2} L_{s}} & 0 \\
\frac{L_{m} R_{r}}{L_{r}} & 0 & -\frac{R_{r}}{L_{r}} & \omega_{s}-p \omega_{r} & 0 \\
0 & \frac{L_{m} R_{r}}{L_{r}} & -\left(\omega_{s}-p \omega_{r}\right) & -\frac{R_{r}}{L_{r}} & 0 \\
-\frac{p L_{m}}{J L_{r}} \lambda_{r q} & \frac{p L_{m}}{J L_{r}} \lambda_{r d} & 0 & 0 & 0
\end{array}\right]
\end{aligned}
$$$$
B=\left[\begin{array}{cc}
\frac{1}{\sigma L s} & 0 \\
0 & \frac{1}{\sigma L s} \\
0 & 0 \\
0 & 0 \\
0 & 0
\end{array}\right]
$$$$
C=\left[\begin{array}{lllll}
1 & 0 & 0 & 0 & 0 \\
0 & 1 & 0 & 0 & 0 \\
0 & 0 & 0 & 0 & 1
\end{array}\right]
$$$$
D=\left[\begin{array}{c}
\frac{2 \eta_{c c}}{3 R_{s}} \mathcal{P}(-p \gamma) \mathcal{Q}\left(p \gamma_{c c}\right) \mathcal{P}(p \gamma) \\
0
\end{array}\right]
$$$$
\mathcal{P}(\theta)=\left[\begin{array}{cc}
\cos (\theta) & \cos \left(\theta+\frac{\pi}{2}\right) \\
\sin (\theta) & \sin \left(\theta+\frac{\pi}{2}\right)
\end{array}\right]
$$$$
\mathcal{Q}(\theta)=\left[\begin{array}{cc}
\cos (\theta)^{2} & \cos (\theta) \sin (\theta) \\
\cos (\theta) \sin (\theta) & \sin (\theta)^{2}
\end{array}\right]
$$$$
\sigma=1-\frac{L_{m}^{2}}{L_{r} L_{s}}
$$

and

$i_{d s}, i_{q s} \quad:$ dq stator current

$\lambda_{r d}, \lambda_{r q}: \mathrm{dq}$ rotor flux

$V_{s d}, V_{s q}: \mathrm{dq}$ stator voltage

$\gamma \quad$ : electrical angle

$\omega_{r}, \omega_{s} \quad$ : rotor and electrical speed angle

$R_{s}, R_{r}, L_{s}, L_{r}, L_{m}, p$, and $J$ are stator resistance, rotor resistance, stator inductance, rotor inductance, mutual inductance, pole, and intertia respectively.

The model of faulty condition introduces two parameters to define the stator inter-turn faults.

1. Localitation parameter, $\gamma_{c c}$, is the real angle between the stator inter-turn winding and the first stator-phase axis (phase $a$ ). This parameter can take only three values 0 , $2 \pi / 3$, or $4 \pi / 3$, corresponding, respectively, to a short circuit on stator phase $a, b$, or $c$.

2. Detection parameter, $\eta_{c c}$, is ratio between number of stator inter-turn winding fault and total number of stator inter-turn in one healty phase.

\section{B. Extended State Observer}

In particle filtering, an extended state is used to estimate the state of the unmeasured variable based on the mathematical model of the system, so that the observer can also be used to estimate the error that occurs in a system if the fault is included in the modeling. A system is generally modeled in the form of state space, which can be generally defined as the system equation below [8]:

$$
\begin{aligned}
& \dot{x}=A x+B u \\
& y=C x+D u
\end{aligned}
$$

with

$$
\begin{array}{ll}
A & \text { : state matrix } \\
B & \text { : control matrix } \\
C & \text { : output matrix } \\
D & \text { : noise matrix } \\
x & \text { : state vector } \\
u & \text { : control signal } \\
y & \text { : output vector }
\end{array}
$$

The mathematical model of the observer is the same as the mathematical model of the system so that the observer can estimate the state of the system in the form of a state space equation. To compensate for the effect of stator inter-turn fault that occur on the induction motor at the same time it requires modification of a new observer algorithm, the algorithm is provided by Indriawati, et.al [9]. The effect of adding stator inter-turn fault is represented by the addition of unknown vector inputs (7) and (8), where the matrix acts on a dynamic system and measurements as represented in the equation (3) and (4) [9].

$$
\begin{aligned}
& x(k+1)=A x(k)+B u(k) \\
& y(k)=C x(k)+D u(k)+F_{s} f_{s}(k)
\end{aligned}
$$

with:

$F_{s}=$ fault matrix

Then a new state is added to move the stator inter-turn fault as follows,

$$
\begin{aligned}
& z(k+1)=A_{z} T_{s}(y(k)-z(k))+z(k) \\
& z(k+1)=-A_{z} T_{s} z(k)+A_{z} T_{s}\left(C x(k)+F_{s} f_{s}(k)\right)+z(k)
\end{aligned}
$$

For $A_{z}$ is identity matrix (I) for $A_{z} \in I^{q}$, whereas the matrix of the effect of stator inter-turn fault is defined as $f=f_{s}$. From equation (3) it can be defined a matrix that will be used to get the extended matrix shown in the following equation

$$
\begin{aligned}
& {\left[\begin{array}{l}
x(k+1) \\
z(k+1)
\end{array}\right]=\left[\begin{array}{cc}
A & 0 \\
A_{z} T_{s} C & -A_{z} T_{s}+I
\end{array}\right]\left[\begin{array}{l}
x(k) \\
z(k)
\end{array}\right]+\left[\begin{array}{l}
B \\
0
\end{array}\right] u+\left[\begin{array}{c}
0 \\
A_{z} T_{s} F_{s}
\end{array}\right]\left[f_{s}(k)\right]} \\
& y(k)=\left[\begin{array}{ll}
0 & I
\end{array}\right]\left[\begin{array}{l}
x(k) \\
z(k)
\end{array}\right]
\end{aligned}
$$

So equations (9) and (10) can be converted into state space equation form,

$$
\begin{aligned}
& \bar{x}(k+1)=\bar{A} \bar{x}(k)+\bar{B} u(k)+\bar{F} f_{s}(k) \\
& z(k)=\bar{y}(k)=\bar{C} \bar{x}(k)
\end{aligned}
$$


Table 1.

The value of parameters

\begin{tabular}{|c|c|c|c|c|}
\hline \multicolumn{3}{|l|}{ Variable } & \multicolumn{2}{|l|}{ Value } \\
\hline \multicolumn{3}{|c|}{ Mutual Inductance $\left(L_{m}\right)$} & \multicolumn{2}{|l|}{$0,258 \mathrm{H}$} \\
\hline \multicolumn{3}{|c|}{ Stator Inductance $\left(L_{s}\right)$} & \multicolumn{2}{|l|}{$0,274 \mathrm{H}$} \\
\hline \multicolumn{3}{|c|}{ Rotor Inductance $\left(L_{r}\right)$} & \multicolumn{2}{|l|}{$0,274 \mathrm{H}$} \\
\hline \multicolumn{3}{|c|}{ Stator Resistance $\left(R_{S}\right)$} & & \\
\hline \multicolumn{3}{|c|}{ Rotor Resistance $\left(R_{r}\right)$} & \multicolumn{2}{|l|}{$3,805 \Omega$} \\
\hline \multicolumn{3}{|c|}{ Inertia $(J)$} & 0,031 & \\
\hline \multicolumn{3}{|c|}{ Pole $(p)$} & 2 & \\
\hline \multicolumn{3}{|c|}{ Electrical angular speed $\left(\omega_{s}\right)$} & \multicolumn{2}{|l|}{$100 \pi$} \\
\hline \multicolumn{3}{|c|}{ Time Sampling $\left(T_{S}\right)$} & \multicolumn{2}{|l|}{$10-6 \mathrm{~s}$} \\
\hline \multicolumn{5}{|c|}{$\begin{array}{c}\text { Table } 2 . \\
\text { RMSE value }\end{array}$} \\
\hline \multirow{2}{*}{$\begin{array}{l}\text { Number } \\
\text { of } \\
\text { Particles }\end{array}$} & \multicolumn{2}{|c|}{$\eta_{c c}$ ramp signal } & \multicolumn{2}{|c|}{$\eta_{c c}$ step signal } \\
\hline & $\begin{array}{l}d \text {-current } \\
\text { fault }\end{array}$ & $\begin{array}{l}q \text {-current } \\
\text { fault }\end{array}$ & $\begin{array}{l}d \text {-current } \\
\text { fault }\end{array}$ & $\begin{array}{l}q \text {-current } \\
\text { fault }\end{array}$ \\
\hline 100 & 0.0128 & 0.0144 & 0.2807 & 0.2698 \\
\hline 250 & 0.0123 & 0.0121 & 0.2606 & 0.2498 \\
\hline 500 & 0.0112 & 0.0124 & 0.2373 & 0.2367 \\
\hline
\end{tabular}

Next, a new state containing sensor fault is added to design the observer equation written in the following equation

$\left[\begin{array}{l}\bar{x}(k+1) \\ f(k+1)\end{array}\right]=\left[\begin{array}{cc}\bar{A} & \bar{F} \\ 0 & I\end{array}\right]\left[\begin{array}{l}\bar{x}(k) \\ f(k)\end{array}\right]+\left[\begin{array}{l}\bar{B} \\ 0\end{array}\right] u$

$\hat{y}(k)=\left[\begin{array}{ll}\bar{C} & 0\end{array}\right]\left[\begin{array}{l}\bar{x}(k) \\ f(k)\end{array}\right]$

\section{Particle Filtering}

Particle filtering (PF) is an algorithm for estimating the state of a system for non-linear, non-Gaussian systems [5]. As one of the best filtering algorithms, particle filtering has been widely used for estimating the state of dynamic systems that are non-linear in the fields of control and signal processing [5].

Particle filtering is one part of Bayesian filtering whose estimation value is based on the Monte Carlo method. The main idea is to approximate the posterior probability distribution. Sample $\tilde{x}_{t}^{i}$ is called a particle. So the particle shows the possible value of $\tilde{x}_{t}^{i}$. Each particle represents a hypothetical state of the object, with discrete sampling corresponding to probability. Several samples (particles) from the resulting state, each associated with a weight that characterizes the quality of a particular particle. Estimated variables are obtained by adding up all the particles. The main key of particle filtering is to represent the posterior density function of random particles to calculate the weight value which will determine the value of the mean position [10].

There are several particle filtering algorithms and one of them that are often used are Sequential Importance Resampling (SIR). This algorithm can be done recursively and will provide an optimal estimate of the current state in sequence. The SIR filter will be adopted as a basic algorithm for nonlinear filtering [11]. In detail, one can estimate the state vector system using this algorithm at $n T$ time. The steps in particle filtering are as follows [12]:

\section{1) Initialization}

At this stage the initialization of particle filtering parameters is carried out. In addition, at the beginning of the iteration there is a group of samples (particles) that will be distributed randomly and their weights are determined based

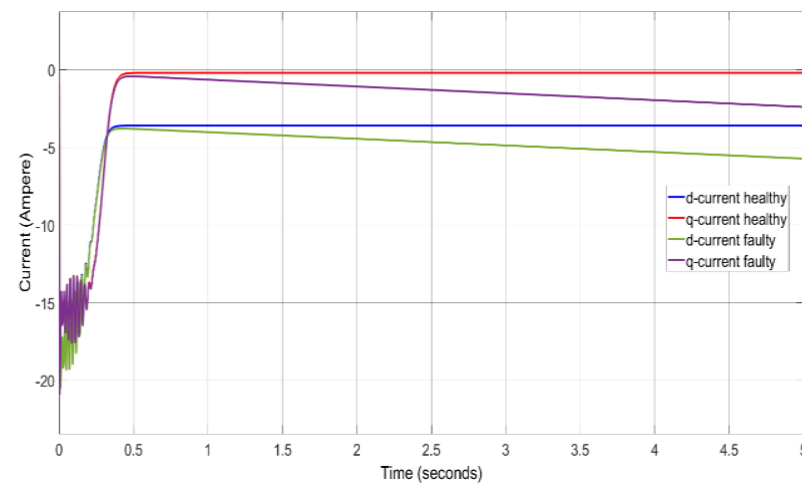

(a)

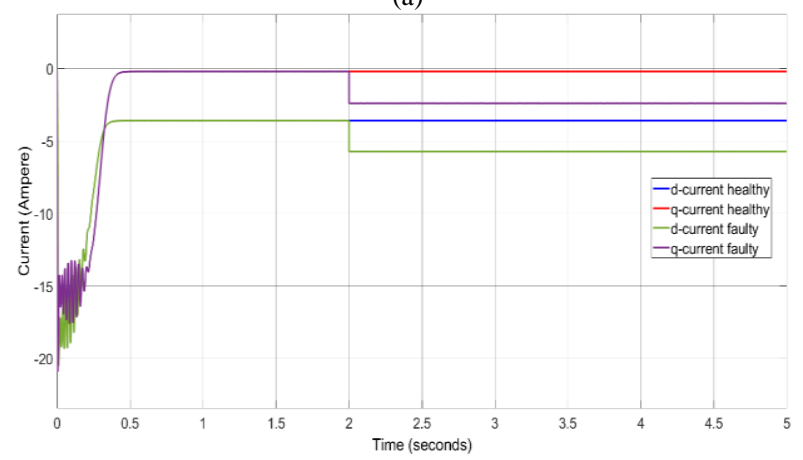

(b)

Figure 2. The effects of stator inter-turn fault on induction motor with: (a) $\eta_{c c}$ ramp signal (b) $\eta_{c c}$ step signal.

on certain distributions. Where it is assumed there are random particles $\left\{x_{p 0}^{i}\right\}_{i=1}^{N} \sim p\left(x_{0}\right), i=1, \ldots \ldots, N$, where $N$ indicates the number of particles with $t:=1$.

\section{2) Particle Updates}

Particle updates are performed to create new transition particle sets. The next particle value is obtained by distributing each particle based on the previous particle value. A number of $\mathrm{N}$ new particles are generated by the following equation:

$x_{p_{t}}^{i} \sim p\left(x_{t} \mid x_{t-1}^{i}\right), \quad i=1, \ldots \ldots, N$

Then for $i=1, \ldots \ldots, N$, the evaluation of particle weights is based on the following equation:

$\widetilde{w}_{t}^{i}=p\left(y_{t} \mid x_{p_{t}}^{i}\right)$

Furthermore, the new weight value is normalized based on the total current weight. Weights are normalized by the following equation:

$w_{t}^{i}=\frac{\widetilde{w}_{t}^{i}}{\sum_{i=1}^{N} \widetilde{w}_{t}^{i}}, \quad i=1, \ldots \ldots, N$

\section{3) Particle Resampling}

After weighting, resampling is done to avoid degeneration of unused particles. Resampling is done by generating a new set of particles based on their weight. In the resampling process, particles with large weights may be selected several times so that there are several different particles occupying the same position. Meanwhile, particles which have relatively low weights will disappear by themselves. For each $i=$ $1, \ldots \ldots, N$, the new particle resampling $x_{t}^{i}$ corresponds to the weight of the particle, where: 
The $6^{\text {th }}$ International Seminar on Science and Technology (ISST) 2020

July $25^{\text {th }} 2020$, Institut Teknologi Sepuluh Nopember, Surabaya, Indonesia

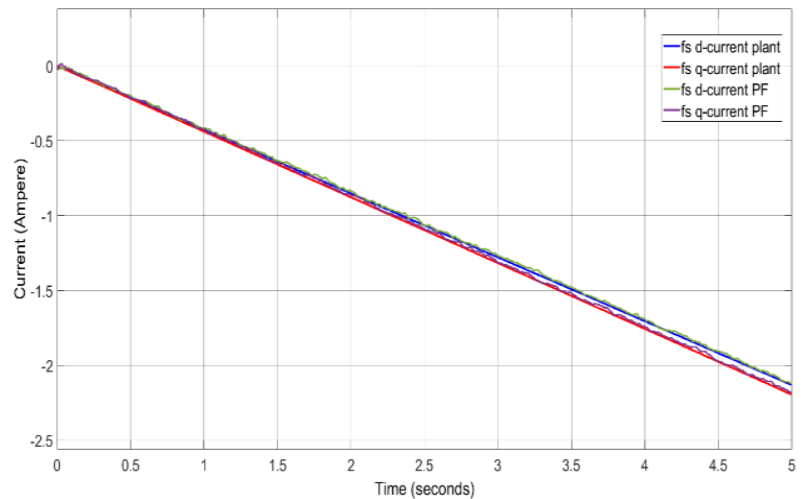

(a)

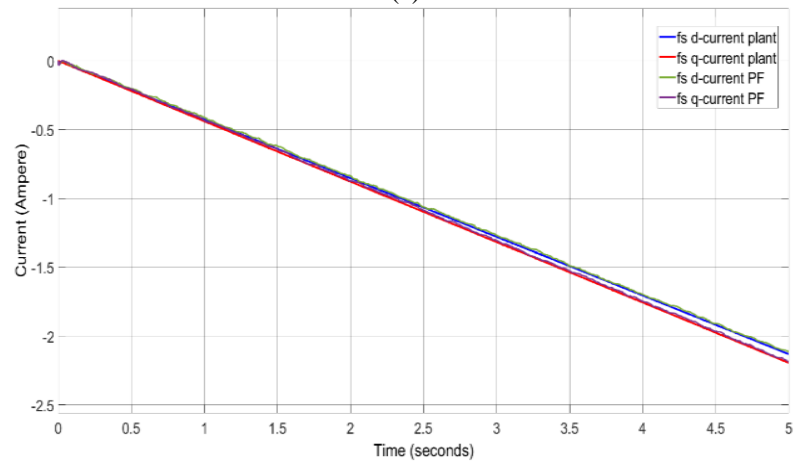

(b)

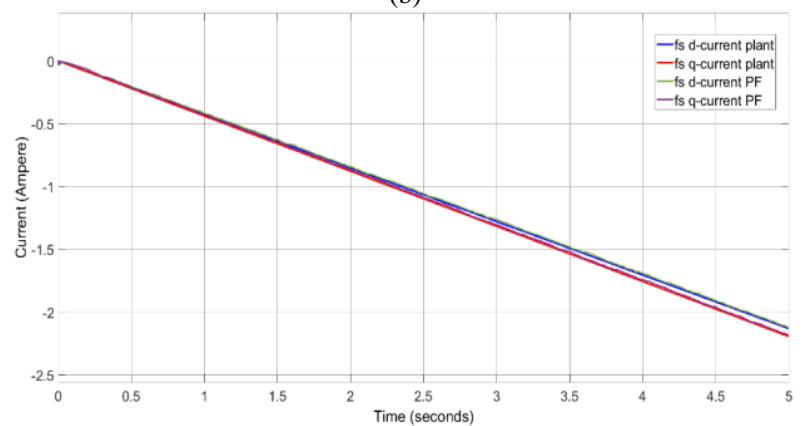

(c)

Figure 3. The fault estimation results using $\eta_{c c}$ ramp signal with: (a) 100 particles, (b)250 particles, (c)500 particles.

$P=\left(x_{t}^{i}=x_{t}^{k}\right)=w_{t}^{k}, \quad k=1, \ldots \ldots, N$

Then return to step 2 .

\section{RESULTS AND DISCUSSION}

In this paper, an induction motor with 2 pole $1.5 \mathrm{~kW}$ was used to illustrate the effectiveness of the proposed approach for this research. The value of this induction motor parameters are listed in Table 1, which was adopted from the work of Allaoui et al [13].

To evaluate the performance of fault estimation using PF, two sets of signal is used to represent the stator inter-turn fault on induction motor. This two sets of signal is represented by ramp and step signal for detection parameter $\eta_{c c}$ with values are

$\eta_{c c, 1}(t)=\eta_{c c, 1}(t-1)+0.02 t+\varepsilon_{n}$

and

$\eta_{c c, 2}(t)=\left\{\begin{array}{l}0+\varepsilon_{n} \text { if } t<2 s \\ 0.1+\varepsilon_{n} \text { if } t \geq 2 s\end{array}\right.$

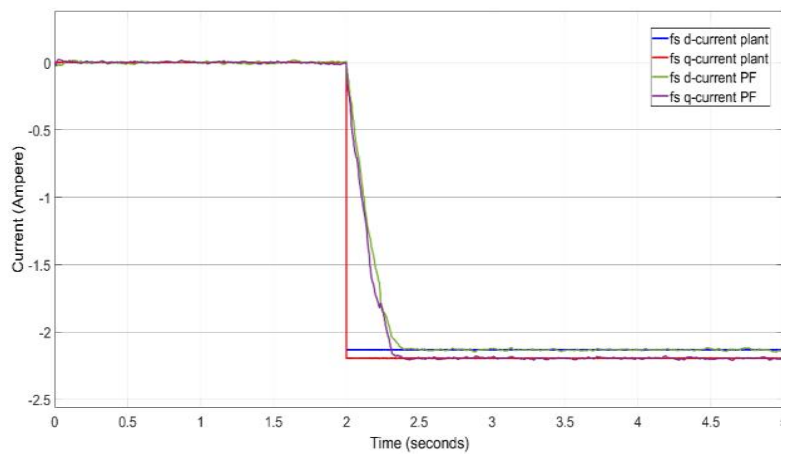

(a)

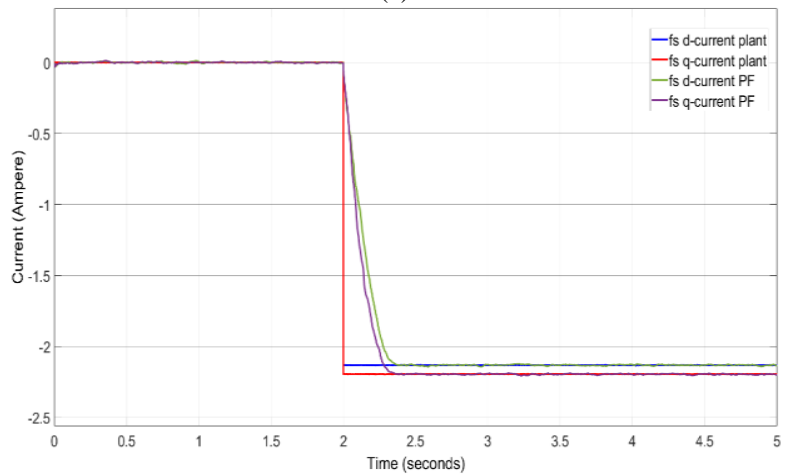

(b)

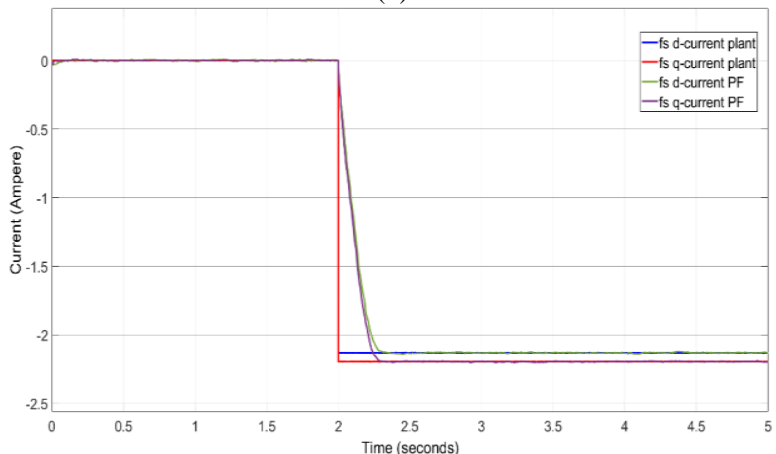

(c)

Figure 4. The fault estimation results using $\eta_{c c}$ step signal with: (a)100 particles, (b)250 particles, (c)500 particles.

where $\eta_{c c, 1}(0)=0, \varepsilon_{n}$ is random error values with means 0 and the variances $1 \times 10^{-8}$.

The effect of this two signal faults on induction motor $d q$ current are provided in Figure 2. It can be seen that at first the current changes in value (transient condition) first before reaching steady state condition. The change in value occurs at 0 to 0.4 seconds, after that its starts to reach steady state condition. It can be seen in the Figure 2, that the $i_{d s}$ current increases from $-20 \mathrm{~A}$ to $-3.5 \mathrm{~A}$ in 0.4 seconds, then the response is steady at a value of $-3.59 \mathrm{~A}$. While the $i_{d s}$ current go through transient condition from $-20.5 \mathrm{~A}$ to $0.2 \mathrm{~A}$ in 0.4 seconds and then the response is steady at a peak value of $0.2 \mathrm{~A}$. When faults is given in phase $a$, the value of both $d q$ current will decreases. This is due to the short-circuit current that occurs, so the stator current will decrease.

Fault estimation is done by using particle filtering with using $\eta_{c c}$ ramp and step signal to represent the stator interturn fault. Variations given by the number of particles used for PF are 100, 250, and 500 particles. Then, the RMSE value is used to measuring the performance of PF for those particles. The results of fault estimation using 100, 250, and 
500 particles when using $\eta_{c c}$ ramp signal from equation (19) are provided in Figure 3.

Figure 3 shows the comparison between the response of the plant output fault with the response of fault estimation using 100,250 , and 500 particles when using $\eta_{c c}$ ramp signal. The blue and red line show the results of $d q$ plant output fault and the green and purple line show the results of $d q$ fault estimation respectively. From Figure 3, it is known that the $d q$ current fault estimation response results are able to approach the results of fault in real plant on both $d q$ axes for all the three particles variations. It can be seen at Figure 3 that the more particles used, the error between PF results and real plant fault is smaller.

The results of fault estimation using 100, 250, and 500 particles when using $\eta_{c c}$ step signal from equation (20) are provided in Figure 3.

Figure 4 shows the comparison between the response of the plant output fault with the response of fault estimation using 100,250 , and 500 particles when using $\eta_{c c}$ step signal. The blue and red line show the results of $d q$ plant output fault and the green and purple line show the results of $d q$ fault estimation respectively. From Figure 4, it is known that the $d q$ current fault estimation response results are able to approach the results of plant modeling on both $d q$ axes at the steady state. When $\eta_{c c}$ value is dropped from 0 to -2.2 instantly, fault estimation response seem difficult to approaching the plant output fault and require a certain amount of time to approach it. It can be seen from Figure 4 that the more particles used, the noise that produced by PF is smaller and the time needed to approach the plant output fault when in the transient condition is faster.

RMSE is used to measure the performance of the fault estimation result. The RMSE results of all three particle variations when using $\eta_{c c}$ ramp and step signal are provided in Table 2 below. It can be seen that when using 500 number of particles, the RMSE value is smaller compared to 100 and 250 partciles used. The RMSE can be seen in Table 2 .

\section{IV.CONCLUSION}

This paper has proposed a fault estimation on induction motor based on stator inter-turn fault. Based on induction motor plant modelling, this approach connects particle filtering with extended state observer equations to provide fault estimation results. The effectiveness of the whole approach is validated by use of a computer simulation about an induction motor system with using two fault signal represented by $\eta_{c c}$ ramp and step signal. The performances of this fault estimation are measured by RMSE and with using 500 particles has smallest RMSE value, which are 0.0112 and 0.0124 for $d q$ current fault when using $\eta_{c c}$ ramp signal and 0.2373 and 0.2367 for $d q$ current fault when using $\eta_{c c}$ step signal

This paper has just provided primary discussions about fault estimation based on on stator inter-turn fault, and many issues are to be further addressed. For example, in the case that the fault acts as a multiplicative input of the dynamic system more elaborate approaches are expected to be proposed.

\section{REFERENCES}

[1] T. Yektaniroumand, M. N. Azari, and M. Gholami, "Optimal Rotor Fault Detection in Induction Motor Using Particle-Swarm Optimization Optimized Neural Network," Int. J. Eng., vol. 31, no. 11, pp. 1876-1882, 2018.

[2] G. B. Kliman, W. J. Premerlani, R. A. Koegl, and D. Hoeweler, “A new approach to on-line turn fault detection in AC motors," pp. 687-693, 2002.

[3] J. Yun, K. Lee, K. W. Lee, S. Bin Lee, and J. Y. Yoo, "Detection and classification of stator turn faults and high-resistance electrical connections for induction machines," IEEE Trans. Ind. Appl., vol. 45, no. 2, pp. 666-675, 2009.

[4] S. Williamson and K. Mirzoian, "Analysis of Cage Induction Motors with Stator Winding Faults Line-End Coils of Induction Motors," no. July, pp. 50-51, 1985 .

[5] C. Andrieu, A. Doucet, and S. S. Singh, "Particle Methods for Change Detection, System Identification, and Control," Proc. IEEE, vol. 92 , no. 3, pp. 423-438, 2004.

[6] T. F. Chan and K. Shi, Applied Intelligent Control of Induction Motor Drives. 2011.

[7] E. Schaeffer and S. Bachir, "Modeling Induction Machine Winding Faults for Diagnosis," in Electrical Machine Diagnosis, 2013, pp. 2368.

[8] K. Ogata, Modern Control Engineering, 3rd ed. New Jersey: Prentice Hall, 1997.

[9] K. Indriawati, T. Agustinah, and A. Jazidie, "Robust Observer-Based Fault Tolerant Tracking Control for Linear Systems with Simultaneous Actuator and Sensor Faults: Application to a DC Motor System," Int. Rev. Model. Simulations, vol. 8, pp. 410-417, 2020.

[10] N. K. Ki and E. J. Delp, "New Models For Real-Time Tracking Using Particle Filtering," Proc. SPIE, vol. 7257, 2009.

[11] N. J. Gordon, D. J. Salmond, and A. F. M. Smith, "Novel approach to nonlinear/non-Gaussian Bayesian state estimation," IEE Proc. F Radar Signal Process., vol. 140, pp. 107-113, 1993.

[12] T. B. Schön, "Solving Nonlinear State Estimation Problems Using Particle Filters - An Engineering Perspective Abstract," 2010.

[13] S. Allaoui, K. Chafaa, Y. Laamari, and B. Athamena, "Induction Motor State Estimation using Tuned Extended Kalman Filter," 2015 4th Int. Conf. Electr. Eng., pp. 1-5, 2015. 